\title{
ESTUDOS SEDIMENTOLÓGICOS DA FORMACÃO AREADO, CRETÁCEO DA BACIA SANFRANCISCANA, MG
}

\author{
JOSÉ HUMBERTO BARCELOS* e KENITIRO SUGUIO**
}

\begin{abstract}
Sedimentological studies involving grain size, heavy mineral and clay mineral analysis were carried on sample from Areado Formation. Lithologically, this formations is constituted by fine-to-very-fine and silty sandstones, rarely conglomeratic. They are mineralogically immature and the heavy mineral assemblage is formed of staurolite, epidote, kyanite and garnet, whose source rocks belong to Araxá, Canastra and Bambuí Groups and Botucatu Formation. These scdiments have been deposited by a fluvial system which changed between changed meandering pelitic to psamitic as a function of climate during their sedimentation.
\end{abstract}

INTRODUÇÃ̃o A Bacia Sanfranciscana é constituída pelas formaçð̃es cretáceas Areado, Urucuia, Capacete e Patos, que jazem em discordância angular sobre as rochas pré-cambrianas dos grupos Araxá, Canastra e Bambuí. Estudos regionais e estratigráficos desses depósitos foram realizados por Barcelos e Suguio (1980).

Este trabalho tem a pretensão de fornecer mais alguns subsídios para melhor caracterizar a Formação Areado, a qual representa a principal e mais importante seqüência sedimentar da referida bacia. Apresenta mais de $230 \mathrm{~m}$ de depósitos de planície de inundação e de canais. Caracteriza-se por apresentar abundantes estruturas sedimentares, principalmente estratificações plano-paralelas e cruzadas tangenciais, e estruturas de escorregamento e deslizamento presentes em siltitos, argilitos e folhelhos silticoarenosos de cores verde-oliva pálido e amarelo esverdeado pálido, e arenitos finos, muitos finos e sílticos, raros grosseiros a conglomerados, com matriz caulinítica e montmorilonítica, de cores castanho-avermelhado e rosalaranja e castanho-amarelado.

Durante os trabalhos de campo foram coletadas 171 amostras de sedimentos da Formação Areado e para fins comparativos, dezessete amostras da Formação Urucuia, seis da Formação Botucatu e cinco de metassedimentos do Grupo Bambuí. Esta amostragem teve por finalidade a obtenção de materiais suficientes para o estudo de granulometria, minerais pesado e minerais de argila. Geograficamente, essas amostras provêm, na quase totalidade, do Alto Paranaíba (Fig. 1) e, para comparação das características sedimentológicas, seis amostras foram coletadas no Triângulo Mineiro (Formação Botucatu).

\footnotetext{
ESTUdOS SEDIMENTOLógicos Análises Granulométricas As análises para o estudo da distribuição granulométrica das amostras foram realizadas pelos processos convencionais descritos por Suguio (1973).

Para os cálculos dos parâmetros estatísticos de distribuição foram usadas as fórmulas propostas por Folk $\mathrm{e}$ Ward (1957).

Como dados, foram utilizadas as porcentagens de ca-
}

da classe granulométrica, porcentagens acumuladas e os parâmetros estatísticos para distribuição total (intervalos areia, silte e argila) e para distribuição apenas do intervalo areia.

Os sedimentos da Formação Areado são litologicamente constituídos por arenitos pelíticos, predominando em $87 \%$ das amostras analisadas arenitos finos, muito finos e sílticos. A seleção em $\mathbf{9 8 \%}$ das amostras varia de pobre a muito pobre, com assimetria predominantemente muito positiva (85\% das amostras), indicando pior seleção para o lado dos clásticos finos e, finalmente, a curtose apresenta-se com curvas, em $62 \%$ das amostras, variando de leptocúrtica a muito leptocúrtica.

Essas características foram também encontradas em sedimentos das formaçð̃es Urucuia e Botucatu; o Grupo Bambuí apresentou predomínio da fração síltica.

$\mathrm{Na}$ análise do intervalo areia $(2,0$ a $0,062 \mathrm{~mm})$ verificou-se que $98 \%$ das amostras se apresentam com diâmetro variando de areia média a fina, com seleção (82\%) moderadamente selecionada evidenciando grande homogeneidade. Como era de esperar, ocorreu a tendência de melhorar o grau de seleção das amostras, pois as fraçôes sílticas e argilosas foram eliminadas. A simetria em $66 \%$ das amostras apresentou-se com curvas aproximadamente simétricas e com assimetria negativa, com pior seleção para as classes de areia mais grossa e, entre $79 \%$ das amostras, as curva se apresentam variando de mesocúrtica a platicúrticas, confirmando a homogeneidade granulométrica.

Semelhantes tendências são exibidas pelas amostras das formações Urucuia e Botucatu. As amostras do Grupo Bambuí constituem-se de sedimentos mais finos.

Quanto à frequêencia do número de classes texturais, cujo parâmetro é também indicativo de seleção, sendo inversamente proporcional a mesma, observou-se que as amostras da Formação Areado são extremamente homogêneas, apresentando $96 \%$ de casos com nove a dez classes, segundo a escala de Wentworth (1922) indicando baixa seleção.

Enquanto as amostras da Formação Urucuia e do Grupo Bambuí apresentam essas mesmas características,

* Departamento de Geologia Geral e Aplicada, IGCE/UNESP, Campus de Rio Claro - 13500 Rio Claro - Pesquisador do CNPq. ** Departamento de Paleontologia e Estratigrafia, IG/USP - Caixa Postal 20899 - São Paulo 


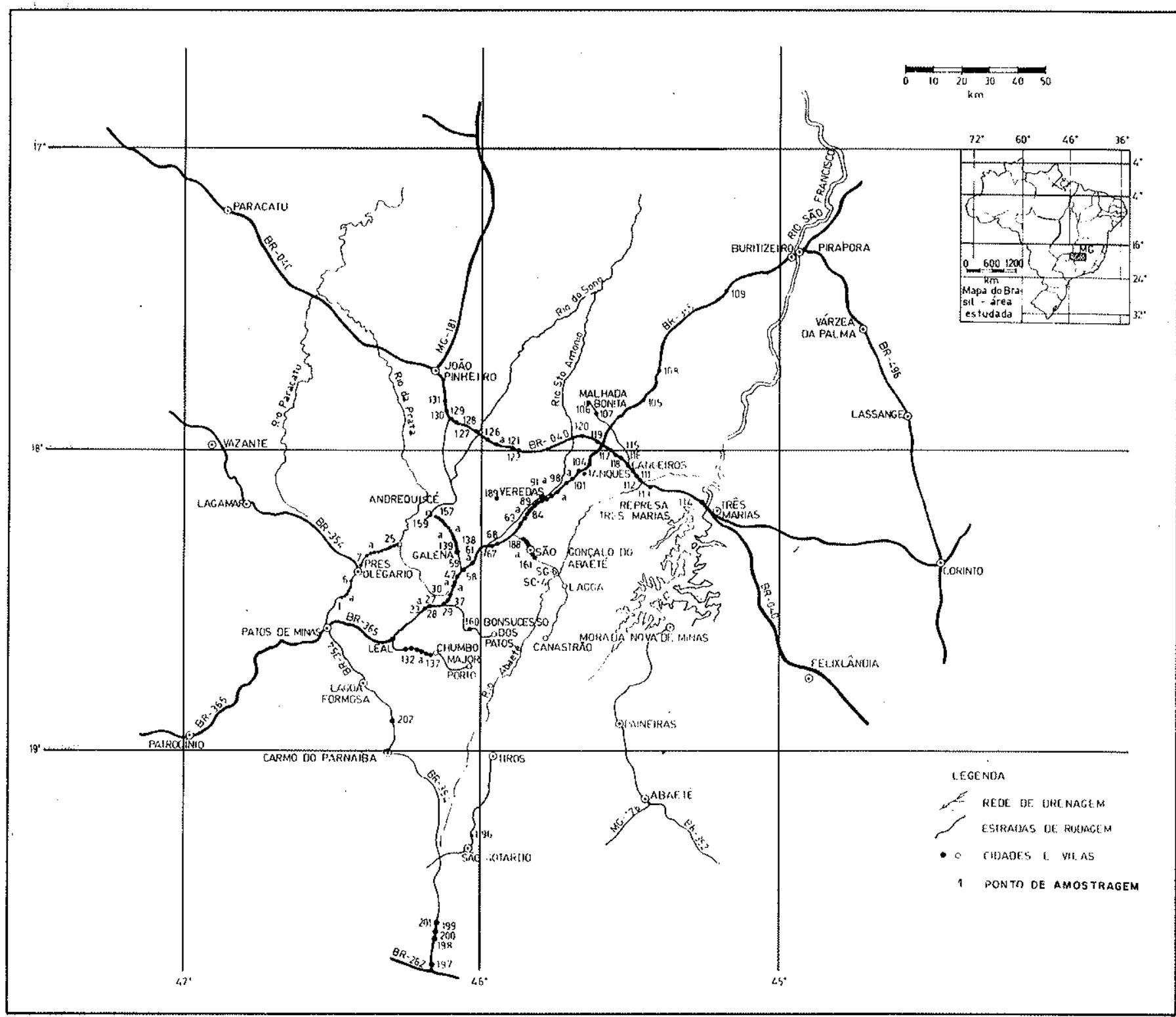

Figura l - Mapa da área de estudo com indicaçao dos pontos de amostragem

a Formação Botucatu é mais heterogênea, variando de oito a onze o número de classes texturais.

Distribuição regional dos parâmetros sedimentológicos Para estudos sobre a distribuição regional de parâmetros granulométricos poder-se-ia aplicar a técnica de análise de superfície de tendência. Neste trabalho não foi possivel sua aplicação porque os pontos de amostragem estão muito concentrados em certas áreas e seria necessária uma distribuição geográfica mais homogênea das amostras.

Por isso os valores dos parâmetros sedimentológicos foram plotados manualmente em um mapa da área, obtendo-se então uma idéia das distribuições regionais, que são em seguida discutidas. Os parâmetros granulométricos utilizados neste estudo foram: porcentagem de areia, porcentagem de silte + argila, porcentagem de argila $e$ relação grosso/fino.

De uma maneira geral, a porcentagem de areia tende a aumentar para oeste e a diminuir para sudeste e leste. Entre Patos de Minas e Presidente Olegário predomina o in tervalo de $50 \%$ a $75 \%$ de areia e, de Presidente Olegário ao Rio da Prata, o intervalo está em torno de $75 \%$ a $100 \%$. Na BR-365, próximo ao contato das formações Patos e Areado, o intervalo de freqüência de areia é de $75 \%$ a $100 \%$, variando deste local até Pirapora de $50 \%$ a $100 \%$ mas predominando o intervalo de $50 \%$ a $75 \%$. Na BR-040, predomina o intervalo de $50 \%$ a $75 \%$, decrescendo para $25 \%$ a $50 \%$ em direção a Três Marias e aumentando para João Pinheiro de $75 \%$ a $100 \%$. Entre Andrequicé e a BR-365, predomina o intervalo de $75 \%$ a $100 \%$ mas, em alguns pontos, situa-se entre $50 \%$ a $75 \%$. Entre Leal e Chumbo predomina o intervalo de $50 \%$ a $75 \%$ e só próximo aos contatos da Formação Areado. Com o Grupo Bambuí ocorre o intervalo de $50 \%$ a $75 \%$. Na região de São Gonçalo do Abaeté, próximo ao contato com o Grupo Bambuí, o intervalo é de $25 \%$ a $50 \%$ aumentando para $50 \%$ a $75 \%$ e $75 \%$ a $100 \%$ em direção à BR-365.

O parâmetro porcentagem de silte + argila é complementar do anterior, sendo então as tendências exatamente inversas. 
O teor médio de argila é da ordem de $0 \%$ a $25 \%$ para toda a região. Maiores valores, como de $50 \%$ a $75 \%$, são encontrados próximos ao Rio da Prata em amostras pertencentes ao subambiente de planície de inundação. $\mathrm{Na}$ região de São Gonçalo do Abaeté até o trevo da BR-040 o teor de argila varia entre $25 \%$ e $50 \%$.

O parâmetro razão grosso/fino, também denominado razão clástica, representa a relação entre a quantidade de cascalho + areia e a quantidade de silte + argila. É um indicador de energia do ambiente de deposição. Parece haver uma tendência para esta relação aumentar para SW e diminuir para NE. Os valores menores, entre 0 e 5 , são encontrados nas áreas de Canoeiros, Chumbo e Andrequicé. A faixa com maior razão clástica e, portanto, indicativa de maior energia, situa-se entre Galena, São Gonçalo do Abaeté e o trevo BR-365 x BR-040, região onde estão localizados os melhores afloramentos do subambiente de canal da Formação Areado.

Minerais pesados Os minerais pesados foram separados em duas frações: de 0,250 a $0,125 \mathrm{~mm}$ e de 0,125 a $0,062 \mathrm{~mm}$ de diâmetro. A separação entre minerais leves e pesados foi feita com auxílio de bromofórmio, segundo a técnica descrita por Krumbein e Pettijohn (1938). Os opacos magnéticos foram eliminados com um ímã manual. A seguir, foram montadas lâminas com as fraçð̃es pesadas das duas granulações, usando-se como meio o bálsamo-do-canadá.

A freqüência relativa de cada mineral foi obtida após a contagem de 100 grãos pesados transparentes nãomicáceos por fração analisada.

FEIÇÕES PRINCIPAIS E FREQUं $\hat{E N C I A ~ D O S ~ M I N E-~}$ RAIS PESADOS TRANSPARENTES NAOO$M I C A ́ C E O S$ Serão descritas as feições principais dos minerais pesados transparentes não-micáceos ordenados por frequiência de ocorrência decrescente.

Estaurolita - Apresenta cores amarela, vermelhaamarelada e rósea. Ocorre nas formas euédrica e anédrica. Exibe bordas com serrilhado paralelo ao eixo $c$, sendo também comuns evidências de dissolução, conferindo à superfície do mineral um padrão reticulado que lembra escamas (Figs. $2 a$ a $2 g$, Estampa 1).

Epídoto - Predominam as cores esverdeada, verdelimão (pistachita), aparecendo ainda os de cor verde-claro (zoisita) a incolor (clinozoisita). Ocorre em formas alongadas, eqüidimensionais, arredondadas ou subarredondadas. Alguns grãos apresentam alteraçőes superficiais formando escamas como na estaurolita (Figs. $3 a$ a $3 c$, Estampa 1).

Turmalina - Predominam as formas eqüidimensionais ("esféricas") bem arredondadas, seguidas das formas prismáticas de bordos arredondados. Ocorrem com mais frequiência os grãos de coloração castanha de turmalinas ferromagnesianas, seguidos das variedades amarela (magnesiana), azul (indicolita), verde (shorlita) e a incolor (acroita) (Figs. $4 a$ a $4 d$, Estampa 2).

Zircão - É mais freqüente a variedade incolor, ocorrendo também zircão róseo e amarelo-esverdeado. Predomina a forma eqüidimensional bem arredondada, apa- recendo secundariamente a forma prismática de bordos arredondados bipiramidais (Figs. $5 a$ a $5 c$, Estampa 2).

Rutilo - Apresenta cores avermelhada, amarelada e vermelho-amarelada. As formas são eqüidimensionais e subarredondadas e raramente prismáticas.

Cianita - Aparece mais comumente como grãos incolores exibindo formas alongadas ou eqüidimensionais e alongadas subarredondadas.

Apatita - Aparece como grãos incolores de formas ovóides e alongadas bem arredondadas (Figs. $6 a$ e $6 b$, Estampa 2).

Granada - Predomina as cores de rósea a incolor, sendo mais raras as de coloração amarela, amarelo-esverdeadas e vermelho-amareladas. São mais freqüentes as formas eqüidimensionais ("esféricas"), ocorrendo ainda alterações superficiais formando padrões retangulares ou losangulares na superfície do mineral (Figs. $7 a$ a $7 c$, Estampa 2).

Monazita (traços) - Aparece como grãos incolores ou com cor amarelo-clara, com formas ovóides e eqüidimensionais ("esféricas") bem arredondadas.

Titanita (traços) - Aparece com formas eqüidimensionais ("esféricas") ou ovóides bem arredondados e de coloração amarelo-clara ou incolor.

Brookita - Presença de apenas um grão na amostra 173 (fração fina), com cor amarelada e índice muito alto, fracamente pleocróica, estriado. Dispersão fortíssima fornecendo figuras de interferência definida em que as cores das extremidades opostas do espectro ficam cruzadas. Grão subarredondado.

As freqüencias dos minerais pesados nas duas frações granulométricas analisadas constam nas Tabs. 1 e 2 .

Freqüência média É a média aritmética das freqüências do mineral em todas as amostras analisadas.

Verificou-se que, na

fração 0,250-0,125 mm, predomina estaurolita, seguida de epídoto, perfazendo $75 \%$ dos minerais analisados (Tab. 1).

fração $0,125-0,062 \mathrm{~mm}$, predomina o zircão, seguido de estaurolita, epídoto e turmalina. Perfazem um somatório de frequêencia igual a $85 \%$ do material analisado (Tab. 2).

Comparando as frequiências dos minerais nas duas frações granulométricas, verificou-se que estaurolita e epídoto são freqüentes nas duas frações. São relativamente constantes as freqüências de turmalina e cianita nas duas fraçōes. O zircão é predominante na fração $0,125-0,062 \mathrm{~mm}$. E a granada, freqüente na fração grossa e a apatita, na fração fina.

Freqüência de ocorrência Esta freqüência percentual é obtida dividindo o número de amostras nas quais o mineral está presente pelo número total de amostras.

Verificou-se que, na

fração 0,250-0,125 mm, maior ocorrência, nas amostras analisadas, de estaurolita, seguida de epidoto, turmalina, zircão e cianita (Tab. 1).

fração $0,125 \sim 0,062 \mathrm{~mm}$, maior ocorrência, nas amostras analisadas, de zircão, seguido de estaurolita, turmalina, epídoto, cianita e rutilo (Tab. 2). 


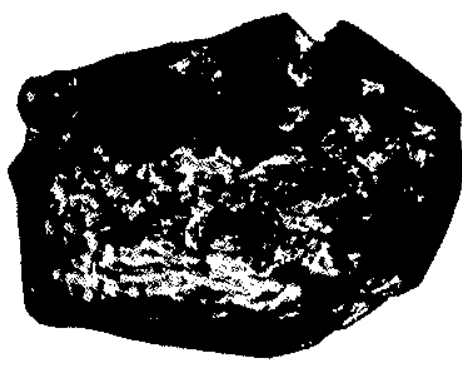

ᄂ

Fig. 20

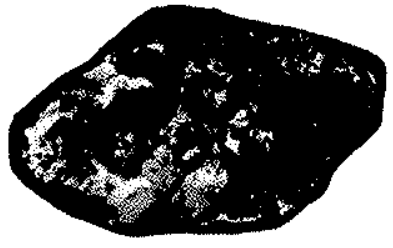

$0, i m m$

Fig. $2 f$

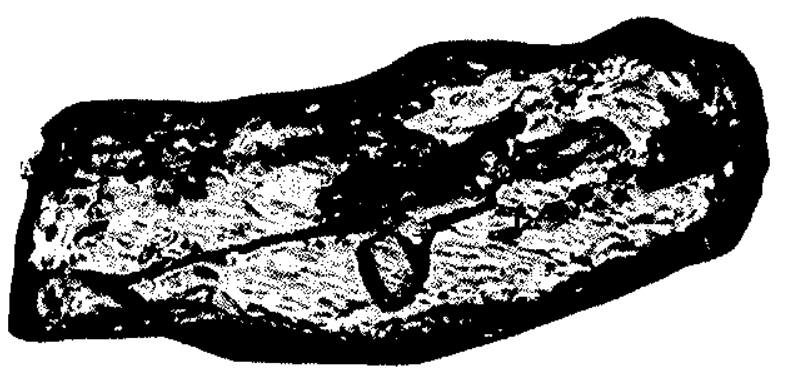

$\frac{0,1 \mathrm{~mm}}{\text { Fig. } 2 \mathrm{~d}}$

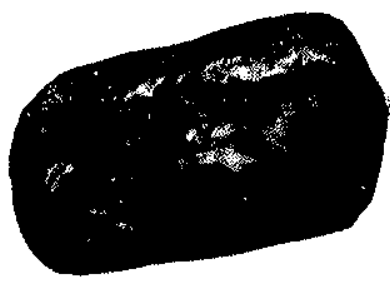

$0,1 \mathrm{~mm}$

Fig. 30

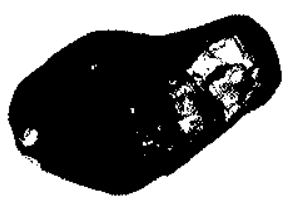

$0,1 \mathrm{~mm}$

Fig. $2 \mathrm{~g}$

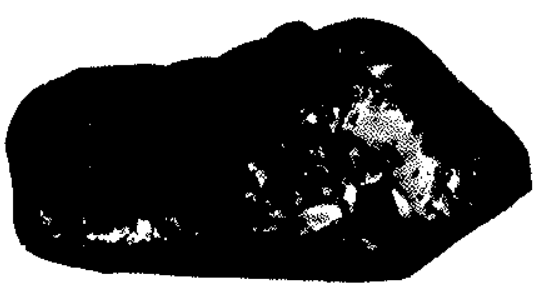

$$
\frac{0,1 \mathrm{~mm}}{\mathrm{Fig} .2 \mathrm{c}}
$$



$\frac{0,1 \mathrm{~mm}}{\text { Fig. } 2 \mathrm{~b}}$

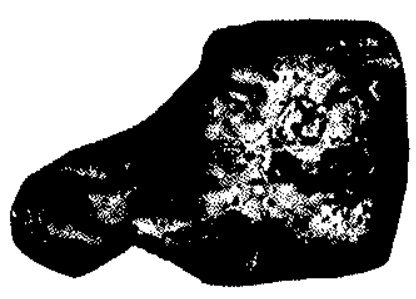

$0,1 \mathrm{~mm}$

Fig. $2 \mathrm{e}$

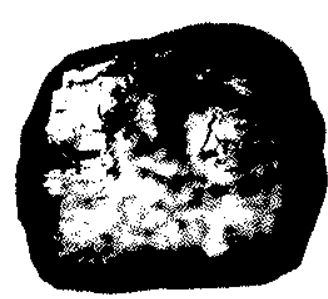

$\frac{0,1 \mathrm{~mm}}{\text { Fig. } 3 \mathrm{c}}$ 




$0,1 \mathrm{~mm}$

Fig. $6 \mathrm{~b}$

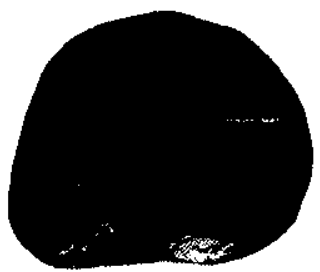

$0,1 \mathrm{~mm}$

Fig. 4 d

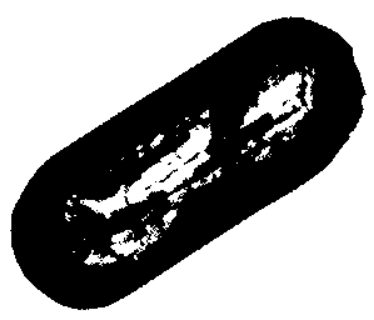

$$
\frac{0,1 \mathrm{~mm}}{\text { Fig. } 50}
$$

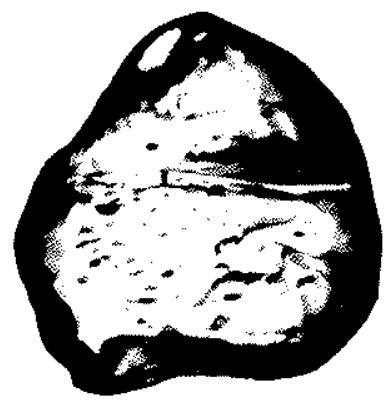

$$
\frac{0,1 \mathrm{~mm}}{\text { Fig. } 7 \mathrm{C}}
$$

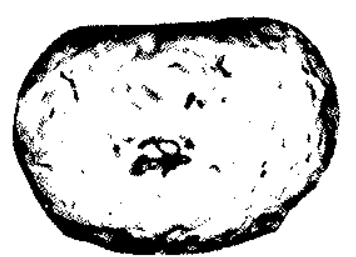

$0,1 \mathrm{~m} \mathrm{~m}$

Fig. $6 a$
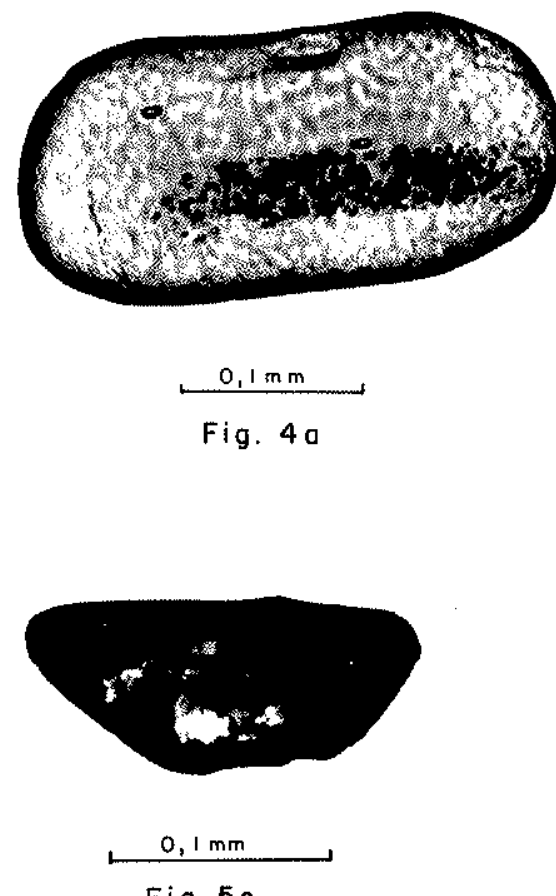

Fig. $5 \mathrm{c}$

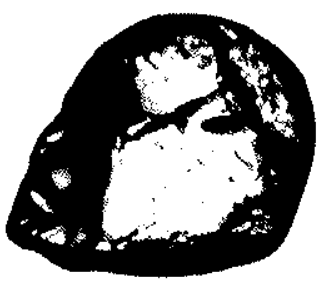

$$
\frac{0,1 \mathrm{~mm}}{\text { Fig. } 7 a}
$$

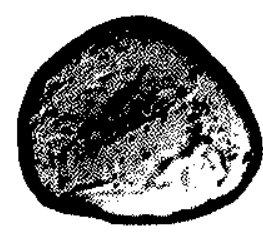

$$
\frac{0,1 \mathrm{~mm}}{\text { Fig. } 4 \mathrm{~b}}
$$

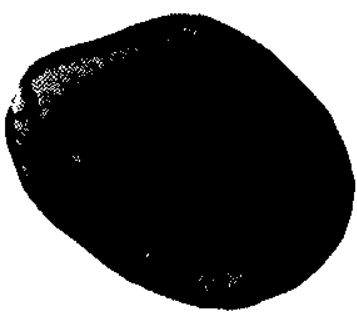

$$
\frac{0,1 \mathrm{~mm}}{\text { Fig. } 4 \mathrm{C}}
$$
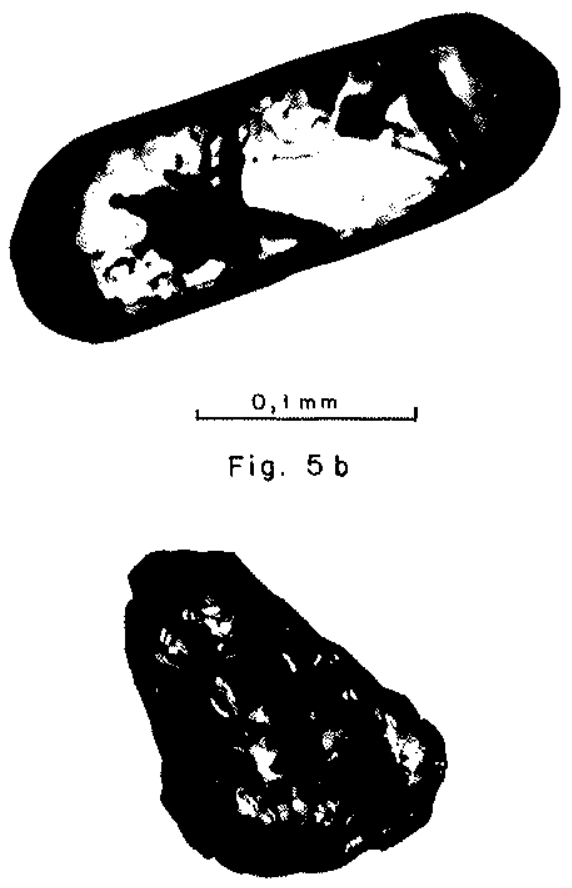

$$
\frac{0.1 \mathrm{~mm}}{\mathrm{Fig} .7 \mathrm{~b}}
$$


Tabela I - Análise de frequiências dos minerais pesados transparentes não-micáceos. Fração 0,250-0,125 mm

\begin{tabular}{l|c|c}
\hline Minerais & $\begin{array}{c}\text { Frequiência } \\
\text { média (\%) }\end{array}$ & $\begin{array}{c}\text { Frequiência de } \\
\text { ocorrência (\%) }\end{array}$ \\
\hline Estaurolita & 61,50 & 99,42 \\
Epidoto & 13,46 & 92,98 \\
Turmalina & 8,23 & 92,98 \\
Zircão & 5,70 & 89,47 \\
Rutilo & 0,18 & 11,11 \\
Cianita & 4,17 & 71,93 \\
Granada & 5,47 & 26,32 \\
Apatita & 0,94 & 12,28 \\
Titanita & 0,02 & 2,34 \\
\hline
\end{tabular}

MATURIDADE MINERALÓGICA As maturidades mineralógica (química) e textural (física) progridem durante o transporte de uma população arenosa, estando, assim, intimamente relacionadas entre si. Consequientemente, um sedimento fisicamente maturo é também quimicamente maturo e vice-versa. A composiçăo mineralógica é essencialmente dependente da proveniência enquanto a composição textural é resultado de processos de transporte e deposição

Utilizando-se a escala de maturidade mineralógica de Sindowsky (in Pettijohn, 1975: 490), verifica-se que a Formação Areado apresenta:

Fração 0,250-0,125 mm

- Predominio de minerais metaestáveis (estaurolita e epídoto).

- Iguais proporções de minerais de alta estabilidade (turmalina) e metaestáveis (granada).

- Iguais proporções de minerais de alta estabilidade (zircão) e minerais metaestáveis (cianita).

Fração 0,125-0,062 mm

- Predomínio de minerais de alta estabilidade (zircão e turmalina).

- Iguais proporçס̃es de minerais de alta estabilidade (turmalina) e minerais metaestáveis (epídoto).
Tabela 2 - Análise de frequêencias dos minerais pesados trans parentes não-micáceos. Fração 0,125-0,062 mm

\begin{tabular}{l|c|c}
\hline Minerais & $\begin{array}{c}\text { Frequiência } \\
\text { média (\%) }\end{array}$ & $\begin{array}{c}\text { Frequiência de } \\
\text { ocorrência (\%) }\end{array}$ \\
\hline Estaurolita & 22,16 & 97,02 \\
Epidoto & 10,60 & 80,36 \\
Turmalina & 10,50 & 93,45 \\
Zircão & 41,90 & 99,40 \\
Rutilo & 2,15 & 70,83 \\
Cianita & 6,51 & 79,76 \\
Granada & 2,33 & 19,64 \\
Apatita & 4,37 & 18,45 \\
\hline
\end{tabular}

- Iguais proporções de minerais de alta estabilidade (zircão) e minerais metaestáveis (estaurolita e epídoto).

Conseqüentemente, a mistura de minerais instáveis com os estáveis permite classificar os sedimentos como mineralogicamente imaturos.

O índice ZTR (zircão + turmalina + rutilo), proposto por Hubert (1962) como indice de maturidade, foi calculado a partir da soma das frequêencias percentuais desses minerais.

Os valores de ZTR foram classificados segundo Coimbra (1976: 25), para facilitar a análise de variaç̋es de frequência. As Tabs. 3 e 4 mostram suas variações nas duas frações analisadas.

$\mathrm{Na}$ fração $0,250-0,125 \mathrm{~mm}$, verificou-se a abundância e a superabundância de minerais instáveis e, em menos de $2 \%$ das amostras, as freqüências são iguais.

$\mathrm{Na}$ fração $0,125-0,062 \mathrm{~mm}$, os minerais estáveis são mais freqüentes, atingindo inclusive $o$ indice de abundância em torno de $35 \%$ mas, em 30\% das amostras, suas frequiências são iguais.

Comparando a Tab. 3 com a Tab. 4 , verifica-se que a fração $0,250-0,125 \mathrm{~mm}$ é predominantemente constituída por minerais instáveis e, na fração $0,125-0,062 \mathrm{~mm}$, o predomínio é de minerais estáveis, mas guardando ainda certo equilíbrio quanto à frequêencia de valores iguais de minerais instáveis e estáveis.

Tabela 3 - Freqüencias de classes do indice ZTR das amostras. Frạ̧ão 0,250-0,125 mm

\begin{tabular}{c|l|c|c}
\hline $\begin{array}{c}\text { ZTR } \\
(\%)\end{array}$ & \multicolumn{1}{c}{$\begin{array}{c}\text { Frequiência } \\
\text { numérica }\end{array}$} & $\begin{array}{c}\text { Frequiência } \\
\text { percentual }\end{array}$ \\
\hline $0-10$ & Superabundância de minerais instáveis & 65 & 38,01 \\
$10-40$ & $\begin{array}{l}\text { Abundância de minerais instáveis } \\
\text { Frequêencias iguais de minerais instáveis e }\end{array}$ & 102 & 59,65 \\
$60-90$ & $\begin{array}{l}\text { estáveis } \\
\text { Abundância de minerais estáveis }\end{array}$ & 4 & 2,34 \\
$90-100$ & Superabundância de minerais estáveis & - & - \\
\hline
\end{tabular}

Tabela 4 - Freqüências de classes do indice ZTR das amostras. Fraçāo 0,125 0,062 mm

\begin{tabular}{c|l|r|r}
\hline $\begin{array}{c}\text { ZTR } \\
(\%)\end{array}$ & \multicolumn{1}{|c|}{$\begin{array}{c}\text { Frequiência } \\
\text { numérica }\end{array}$} & $\begin{array}{r}\text { Frequiência } \\
\text { percentual }\end{array}$ \\
\hline $0-10$ & Superabundância de minerais instáveis & 11 & 6,55 \\
$10-40$ & Abundância de minerais instáveis & 35 & 20,83 \\
$40-60$ & Freqüências iguais de minerais instáveis e & 51 & 30,36 \\
& estáveis & 59 & 35,12 \\
$60-90$ & Abundância de minerais estáveis & 12 & 7,14 \\
$90-100$ & Superabundância de minerais estáveis & & \\
\hline
\end{tabular}




\section{NÚMERO DE ESPÉCIES MINERALÓGICAS}

número de espécies mineralógicas no resíduo pesado de um sedimento está ligado a diversos fatores, sendo os principais: a diversidade litológica de áreas-fontes, o clima desta área e do sítio de deposição, o tectonismo, bem como a ação de prováveis soluções intra-estratais. A diversidade de áreas-fontes e o clima desta área e do sítio de deposição talvez sejam fatores condicionantes da maioria de espécies mineralógicas na área em estudo.

As Tabs. 5 e 6 mostram os resultados de freqüência de número de espécies mineralógicas nas frações pesadas de todas as amostras estudadas.

Pode-se observar que tanto na fração $0,250-0,125 \mathrm{~mm}$ como na $0,125-0,062 \mathrm{~mm}$, são mais frequèten as amostras que se apresentam com quatro a sete espécies mineralógicas.

Comparando a Tab. 5 com a Tab. 6, verifica-se que a diversidade nas duas fraçőes é bem.semelhante e que, na fração $0,250-0,125 \mathrm{~mm}$, são predominantes as amostras com cinco espécies, seguidas de quatro a seis espécies. Já na fração 0,125-0,062 mm, são predominantes as amostras com seis espécies, seguidas de cinco, quatro e sete espécies mineralógicas.

\section{DISTRIBUIÇÃO REGIONAL DOS MINERAIS} PESADOS Utilizando-se método análogo ao aplicado para o estudo da distribuição regional dos parâmetros sedimentológicos, analisou-se a distribuição em área dos minerais pesados transparentes e não-micáceos, da Formação Areado.

Neste estudo, considerou-se superabundante o mineral de freqüência superior a $50 \%$; abundante, entre $10 \%$ e $50 \%$; comum, entre $2 \%$ e $10 \%$; e raro, entre $0 \%$ e $2 \%$, conforme proposição de Coutinho e Coimbra (1974: 32).

\section{Estaurolita}

Fração 0,250-0,125 mm

A estaurolita é superabundante na área, entre Patos de Minas e Presidente Olegário, em todas as amostras coletadas na BR-365 entre Patos de Minas e Pirapora, na maioria das amostras coletadas entre Três Marias e João Pinheiro, próximo a Andrequicé, e nas amostras pertencentes à Formação Urucuia, em São Gonçalo do Abaeté.

É abundante nas proximidades dos rios da Prata e do Sono, de Galena, em todas as amostras coletadas entre Leal e Chumbo, e nas amostras coletadas entre São Gonçalo do Abaeté e o Rio Abaeté.

Fração 0,125-0,062 mm

De uma maneira geral, é abundante em quase todas as amostras desta fração. Comporta-se como comum apenas em algumas amostras coletadas em Canoeiros, Rio do Sono, Leal, Galena e entre São Gonçalo do Abaeté e o Rio Abaeté.

\section{Epidoto}

Fração 0,250-0,125 mm

É abundante na área entre Patos de Minas e Presidente Olegário, Leal e Chumbo, Andrequicé e de São Gonçalo do Abaeté ao Rio Abaeté. Entre Três Marias e João Pinheiro, é predominantemente comum. De Patos de Minas a São Gonçalo do Abaeté, sua freqüência diminui, apresentando-se como raro a comum. Aumenta sua freqüência de São Gonçalo do Abaeté em direção ao trevo da BR-040 x BR-365, com ocorrência inicialmente co- mum passando a abundante. Entre Galena e a BR-365, sua ocorrência é também comum.

Fração 0,125-0,062 mm

Sua frequeência é de abundante a superabundante apenas nas amostras coletadas entre Leal e Chumbo. É comum entre Patos de Minas e Presidente Olegário, e abundante deste local até o Rio da Prata. Entre Patos de Minas e São Gonçalo do Abaeté, é de comum a raro até o trevo com a BR-040. É ainda abundante nas proximidades de Galena, Chumbo e entre São Gonçalo do Abaeté e o Rio Abaeté. Próximo a Andrequicé e de São Gonçalo do Abaeté até a BR-365 sua ocorrência é comum.

\section{Turmalina}

Fração 0,250-0,125 mm

Ocorre como abundante em Canoeiros e entre Leal e Chumbo. É de comum a abundante entre Patos de Minas e Presidente Olegário, diminuindo sua freqüência em direção ao Rio da Prata. Aumenta sua ocorrência de comum para abundante de Patos de Minas a São Gonçalo do Abaeté, diminuindo para raro em direção ao trevo com a BR-040. A frequêencia aumenta de raro para abundante de João Pinheiro a Canoeiros. De Andrequicé em direção à BR-365 aumenta também a freqüência de raro a abundante. Esses mesmos valores são também encontrados desde o Rio Abaeté até a BR-365, passando por São Gonçalo do Abaeté.

Fração $0,125-0,062 \mathrm{~mm}$

Este comportamento de distribuição em área é parcialmente mantido. Apenas nas proximidades do Rio da Prata a frequência é abundante e predominantemente de rara a comum em São Gonçalo do Abaeté.

\section{Zircão}

Fração 0,250-0,125 mm

Este mineral é abundante só no trecho entre Patos de Minas e São Gonçalo do Abaeté e próximo ao Rio

Tabela 5 - Analise de freqüência do número de espécies de minerais pesados transparentes não-micáceos. Fração $0,250-0,125 \mathrm{~mm}$

\begin{tabular}{c|c|c}
\hline $\begin{array}{c}\text { Número de } \\
\text { espécies }\end{array}$ & $\begin{array}{c}\text { Frequiência } \\
\text { numérica }\end{array}$ & $\begin{array}{r}\text { Frequiência } \\
\text { percentual }\end{array}$ \\
\hline 2 & 1 & 0,58 \\
3 & 9 & 5,26 \\
4 & 36 & 21,05 \\
5 & 81 & 47,37 \\
6 & 33 & 19,30 \\
7 & 10 & 5,85 \\
8 & 1 & 0,58 \\
\hline
\end{tabular}

Tabela 6 - Análise de freqüência do número de espécies de minerais pesados transparentes não-micáceos. Fração $0,125 \cdot 0,062 \mathrm{~mm}$

\begin{tabular}{c|c|c}
\hline $\begin{array}{c}\text { Número de } \\
\text { espécies }\end{array}$ & $\begin{array}{c}\text { Freqüência } \\
\text { numérica }\end{array}$ & $\begin{array}{c}\text { Freqiiência } \\
\text { percentual }\end{array}$ \\
\hline 2 & 2 & 1,19 \\
3 & 3 & 1,75 \\
4 & 22 & 13,10 \\
5 & 45 & 26,79 \\
6 & 67 & 39,88 \\
7 & 21 & 12,50 \\
8 & 8 & 4,76 \\
\hline
\end{tabular}


Abaeté. Sua frequêencia aumenta de raro a abundante do Rio da Prata para Patos de Minas. Diminui sua ocorrência de comum para raro de São Gonçalo do Abaeté ao trevo da BR-040. Comporta-se como comum entre Três Marias e João Pinheiro e entre Leal e Chumbo. É abundante na proximidade de Andrequicé, raro em Galena, passando a comum em direção à BR-365. Em São Gonçalo do Abaeté, a freqüência aumenta de raro para comum, também em direção à BR-365.

Fração 0,125-0,062 mm

A freqüência nesta fração é homogênea, predominando o intervalo de abundante a superabundante em todas as amostras analisadas. Não foi possível identificar áreas com predomínio de um dos valores. Os dois são encontrados associados, não ocorrendo o predomínio em área de distribuição de um intervalo sobre o outro.

\section{Cianita}

Fração 0,250-0,125 mm

É abundante apenas nas proximidades do Rio Abaeté, Galena e Tanques. Em todo o restante da área, sua freqüência é de rara a comum, não permitindo identificar áreas de maior ocorrência preferencial.

Fração 0,125-0,062 mm

Apresenta comportamento semelhante. Apenas apresenta frequiência abundante entre São Gonçalo do Abaeté e a BR-365, em Galena e Veredas.

\section{Granada}

Fração 0,250 0,125 mm

É abundante apenas em São Gonçalo do Abaeté, decrescendo sua frequiência em direção à BR-365. É abundante também em Andrequicé e superabundante em Galena. Aumenta sua freqüência de Chumbo para Leal.

Fração 0,125-0,062 mm

A freqüência nesta fração é bem similar, ocorrendo como abundante apenas em Galena. Entre Leal e Chumbo é comum e, em São Gonçalo do Abaeté, decresce sua freqüência de abundante para raro, do Rio Abaeté à BR-365.

\section{Rutilo}

Fração $0,250-0,125 \mathrm{~mm}$

Ocorrência apenas como traços.

Fração 0,125-0,062 mm

A frequêencia deste mineral é significativa apenas na fração fina. É comum entre Patos de Minas e o Rio da Prata, proximidades de Galena, São Gonçalo do Abaeté, Veredas e Canoeiros. No restante da região, sua freqüência é rara nas amostras analisadas.

PROVAVEIS AREAS-FONTES Os minerais pesados encontrados permitiram diagnosticar prováveis áreasfontes específicas e fontes diversificadas.

A estaurolita teve como fonte primária os xistos dos grupos Araxá e Canastra, e, secundariamente, os metarenitos do Grupo Bambuí e arenitos da Formação Botucatu na região de Romaria e vale do Rio Araguari.

$\mathrm{O}$ epídoto proveio de rochas ígneas ácidas (granitos) e metamorfitos dos grupos Araxá, Canastra e metarenitos do Grupo Bambuí.

O zircão, a turmalina e o rutilo seriam oriundos principalmente de rochas ígneas e metamórficas, e aparecem com formas eqüidimensionais muito bem arredondadas, sugerindo os metarenitos do Grupo Bambuí e os arenitos da Formação Botucatu como fonte secundária fornecendo sedimentos preexistentes.

A cianita teria provindo de rochas metamórficas (xistos) do Grupo Araxá, de xistos e quartzitos do Grupo Canastra e secundariamente dos metarenitos do Grupo Bambuí.

A granada parece estar ligada principalmente aos xistos granatíferos do Grupo Araxá que, segundo Barbosa et al. (1970: 21), apresentam como acessório a granada, podendo-se constituir num mineral importante e também a presença marcante de rutilo, zircão, turmalina e estaurolita.

A apatita é um mineral comum em algumas áreas e acessório universal em rochas ígneas e metamórficas.

Análises dos minerais de argila Para efetuar a identificação dos minerais de argila, 74 amostras foram selecionadas entre as coletadas para as análises granulométricas.

O material foi analisado pelo método de difração de raios X segundo técnicas apresentadas por Grim (1953).

Foram identificadas a caulinita e a montmorilonita, estando também presentes mica, quartzo, "camadas mistas" e eventualmente feldspato.

De acordo com Weaver (1958), a caulinita é dominante, principalmente em ambientes fluviais, embora possa ocorrer em abundância em todos os ambientes, e a montmorilonita e as "camadas mistas" podem ocorrer em abundância em quaisquer dos ambientes deposicionais principais.

Milne e Early (1958) consideraram o clima na áreafonte como o fator mais importante na determinação de minerais de argila.

Moniz (1975) postula que a natureza mineralógica dos produtos de alteração das rochas é determinada pelas condiçðes do meio. Assim, em condiçð̋es de lixiviação fraca, em processo denominado bissialitização, forma-se a montmorilonita. Em condiçðes de lixiviação mais forte, o processo dominante é a caulinitização.

Suguio (1969) considerou inadequado descrever o "clima" do ambiente onde se situa o sistema formador de minerais de argila por termos meteorológicos de sentido amplo, preferindo a utilização de parâmetros mais definidos que incluem $\mathrm{pH}$, eH, concentração de íons em reação, como foram estabelecidos por Krumbein e Garrels (1952). Ainda segundo este autor, os minerais de argila do grupo da caulinita são formados sob condições opostas daquelas da gênese da montmorilonita.

A maior parte dos autores atribui à formação de argilas montmoriloníticas um clima semi-árido e existência de silicatos facilmente alteráveis, como as cinzas vulcânicas, mesmo assim nem a semi-aridez, nem as cinzas vulcânicas parecem constituir condiçôes essenciais a sua formação.

Parece que. as condiçð̃es climáticas da área-fonte e da área de deposição seriam mais ou menos similares. $O$ clima quente e relativamente seco (semi-árido) propiciaria as condiçðes necessárias favoráveis à formação da montmorilonita.

Nessas mesmas condições climáticas, os fragmentos de tufo vulcânico foram caulinitizados. 
Diferenças de viscosidade e energia e suas relaçaes com diversos ambientes deposicionais, segundo Sahu (1964) O método de tratamento estatístico desenvolvido por Sahu (1964) mostra muito bem as diferenças de energia e viscosidade e suas relações com os ambientes de deposição de formaçðes sedimentares.

Essas características de energia e viscosidade relativas ao meio deposicional ficam impressas nas distribuiçðes granulométricas dos sedimentos e são expressas pelas variaçðes do conjunto de parâmetros, como diâmetro médio, desvio-padrão e curtose, para dados de cada grupo de amostras, auxiliando na interpretação dos ambientes de deposição de sedimentos.

O primeiro passo na aplicação do processo consiste em organizar as amostras em grupos, procurando verificar a variação de energia e viscosidade na caracterização dos subambientes.

Os grupos tiveram a seguinte organização:

Grupo 1 - Amostras: De 1 a $6=6$

Grupo 2 - Amostras: 7, 8, 9, 10, 12, 14, 15, 16, 17, 21

$$
\text { e } 22=11
$$

Grupo 3 - Amostras: $11,13,18,19$ e $20=5$

Grupo 4 - Amostras: 23, 24, 25, 26, 27, 28, 30, 31, 32 , $33,35,36,37,38,47,48,49,50$, $51,52,53,54,55,56,57,59,67$ e $68=28$

Grupo 5-Amostras: 64,65 e $66=3$

Grupo 6 - Amostras: 70, 72, 74, 75, 84 e $87=6$

Grupo 7 - Amostras: 81 e $82=2$

Grupo 8 - Amostras: 89, 90, 91, 92, 93 e $98=6$

Grupo 9 - Amostras: 99, 101 e $104=3$

Grupo 10 - Amostras: $69,100,102$ e $103=A$

Grupo 11 - Amostras: 106 e $107=2$ (Formação Urucuia)

Grupo 12 - Amostras: 105,108 e $109=3$

Grupo 13 - Amostras: 115,116 e $118=3$
Grupo 14 - Amostras: 119 e $120=2$

Grupo 15 - Amostras: 121,122 e $127=3$

Grupo 16 - Amostras: 123 e $124=2$

Grupo 17 - Amostras: 125 e $126=2$

Grupo 18 - Amostras: 128, 129 e $130=3$

Grupo 19 - Amostras: $133,134,136$ e $137=4$

Grupo 20 - Amostras: 155,158 e $159=3$

Grupo 21 - Amostras: 142, 144, 152 e $153=4$

Grupo 22 - Amostras: 143, 145, 146, 147, 149, 150, 151 e $154=8$

Grupo 23 - Amostras: 138, 139 e $140=3$ (Formação Urucuia)

Grupo 24 - Amostras: 166, 167 e $168=3$

Grupo 25 - Amostras: 169, 170, 171 e $172=4$

Grupo 26 - Amostras: 173,174 e $175=3$

Grupo 27 - Amostras: 177, 178, 179 e $180=8$ (Formação Urucuia)

Grupo 28 - Amostras: $181,182,183,184,185,186=6$ (Formação Urucuia)

ANÁLISE E DISCUSSÃo dOS RESULTADOS OS grupos acusaram em sua grande maioria ambiente nitidamente fluvial, pelo teste de Sahu (Fig. 8). Apenas seis grupos, de números $2,10,17,20,26$ e 27, afastaram-se ligeiramente da faixa de sedimentos fluviais. Estes grupos apresentam condições de menor energia, proporcionando mais condiçóes deposicionais ligadas às caracteristicas do subambiente de planície de inundação.

Os 22 grupos de amostras que exibiram características nitidamente fluviais, mais ligadas às condiçðes energéticas do subambiente de canal, por este teste estatístico variaram consideravelmente em suas energia e viscosidade.

Os grupos 12, 16 e 25 são indicativos de condiçð̃es mais energéticas enquanto os grupos $3,5,6$ e 11 já salientam condições de aumento de viscosidade e, no grupo 14 , as condiçð̃es são de maior viscosidade.

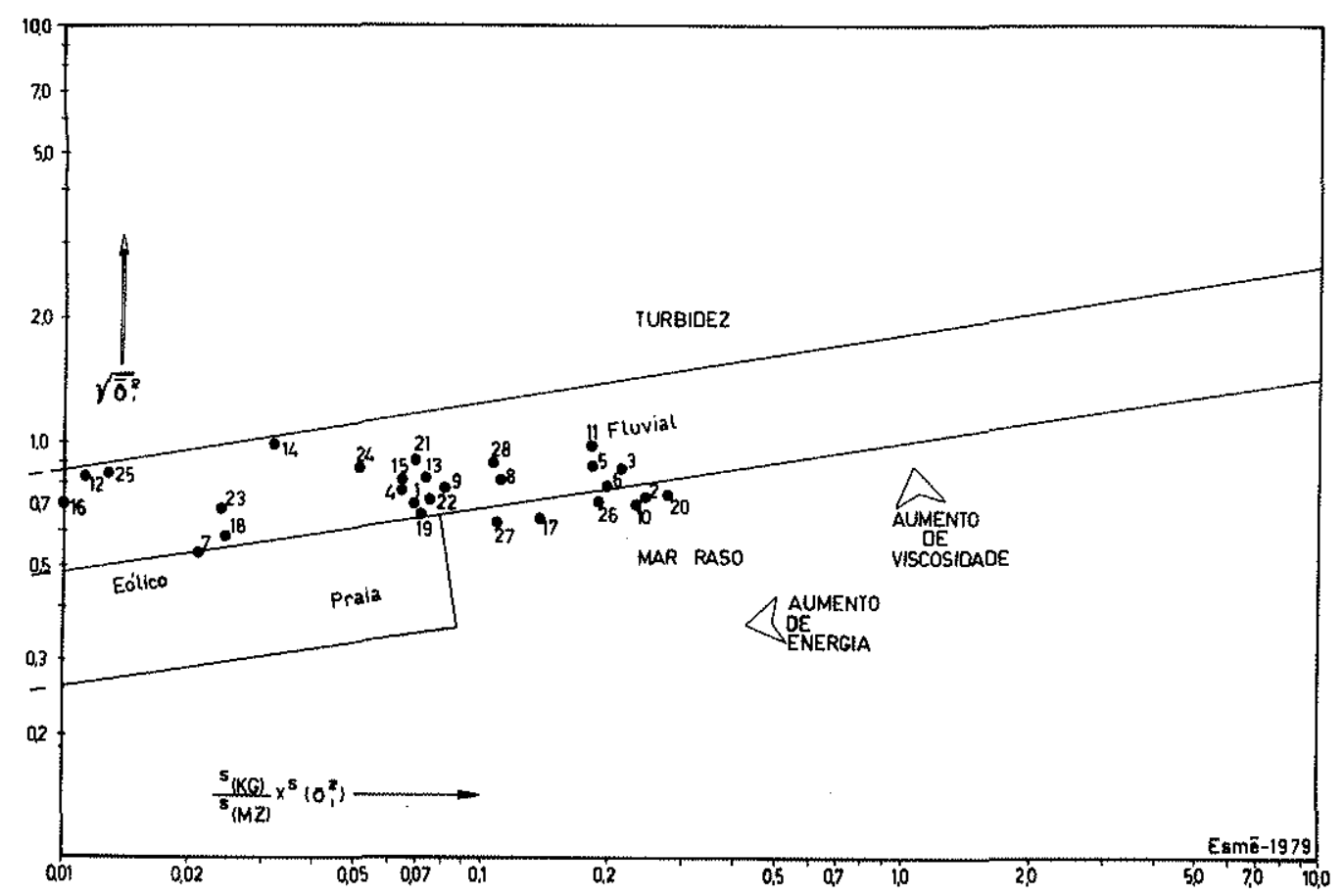

Figura 8 - Diferenças de viscosidade e energia e suas relaçסes com diversos ambientes deposicionais 
Condições de equilíbrio em termos de energia e viscosidade, do meio deposicional, são caracterizadas pelos grupos $1,4,8,9,13,15,21,22,24$ e 28 .

Os grupos $17,18,19$ e 23 apresentam condiçóes de aumento de energia em relação aos outros grupos.

A análise de detalhe dos grupos por área de amostragem revelou resultados mais interessantes.

Os grupos 1, 2 e 3 revelam diferenças de condiçðes de energia do meio deposicional.

Os grupos 1 e 3 , constituídos por amostras de arenitos ricos em estratificaçőes cruzadas, revelam características de condições mais energéticas, sendo esta feição mais evidenciada pelo grupo 1 . O grupo 2 já revela condiçðes de energia e viscosidade mais condizentes com o subambiente de planície de inundação.

As amostras coletadas entre Patos de Minas e Pirapora constituíram os grupos de 4 a 12 .

Os grupos 5, 6 e 11 apresentam condições de aumento da viscosidade, os grupos 4,8 e 9 revelam um aumento de energia e os grupos 7 e 12 apresentam-se com características de maior energia em relação aos outros grupos. $O$ grupo 10 revela situação de equilíbrio quanto à energia $\mathrm{e}$ à viscosidade do meio deposicional.

Das amostras coletadas entre Três Marias e João Pinheiro, formaram-se os grupos de 13 a 18 .

O grupo 17 apresenta condiçðes de equilíbrio. Os grupos $12,14,16$ e 18 mostram as condiçðes de aumento significativo de energia do meio deposicional e, nos grupos 13 e 15 , nota-se o aumento da viscosidade.

O grupo 19, organizado pelas amostras de arenito com raras estratificaçóes cruzadas, coletadas entre Leal e Chumbo, revela as características mais energéticas do ambiente deposicional.

Com as amostras coletadas entre Andrequicé e a BR-365 organizaram-se os grupos 20 e 23. Correlacionando esses grupos com suas posições na seção colunar correspondente foi possível detectar o aumento das condições energéticas do meio deposicional da base para o topo.

As amostras coletadas em São Gonçalo do Abaeté constituíram os grupos 24 a 28 , que revelam marcantes diferenças entre si.

Os grupos 24 e 25 , de características mais energéticas, são constituídos por amostras coletadas na base da seção.
As amostras da parte intermediária da seção formaram os grupos 26 e 27 , que revelam condições de energia e viscosidade mais características do subambiente de planície de inundação. Das amostras coletadas no topo da seção é constituído o grupo 28 (Formação Urucuia) com características de aumento de viscosidade em relação aos outros grupos.

CONSIDERAÇÕES FINAIS A Formação Areado é litologicamente constituída de arenitos finos a muitos finos e sílticos, raros grosseiros e conglomeráticos, com matriz caulinítica e montmorilonítica. Esses sedimentos apresentam moderada maturidade textural e são de pobre a muito pobremente selecionados. Em termos mineralógicos, são imaturos e os minerais pesados são constituídos por uma assembléia simples de minerais quimicamente instáveis com o predomínio de estaurolita, epídoto, cianita e granada, derivados das rochas dos grupos Araxá, Canastra e Bambuí, e da Formação Botucatu.

A contribuição de quartzo para a formação desses arenitos deve estar associada principalmente aos quartzitos do Grupo Espinhaço (Serra do Espinhaço e do Cabral) situados a NE e SE da bacia.

Esses sedimentos foram depositados em subambiente de planície de inundação caracterizado por alternância de arenito fino estratificado com argilito bem laminado e camadas de folhelho síltico-arenoso intercalado com arenito fino a médio, estratificado e/ou maciço. Os sedimentos representados pelos arenitos finos, muitos finos e silticos, raros grosseiros a conglomerados foram depositados em subambiente de canal, representado pelas fácies de depósitos de preenchimento de canais, de barra de canal, de barra de meandro e de leque aluvial.

O sistema fluvial responsável pela formação desses subambientes poderia ser classificado em meandrante pelítico nos períodos mais secos, passando a meandrante psamítico nas faces mais úmidas.

Agradecimentos Os autores expressam seus agradecimentos ao Conselho Nacional de Desenvolvimento Científico e Tecnológico (CNPq) pelo auxílio de pesquisa e bolsa de pesquisa, processos n. 2222.0943/77 e 1111.4005/77, respectivamente, que tornaram possível a realização deste trabalho.

\section{BIBLIOGRAFIA}

BARBOSA, O., BRAUN, O.P.G., DUER, R.C. c CUNHA, C.A.B.R. da -1970 - Geologia da Região do Triângulo Mineiro. Div. Fom. Prod. Min. D.N.P.M., Bol. 136, Rio de Janeiro.

BARCELOS, J.H. e SUGUIO, K. - $1980-$ Distribuição regional e estratigráfica das Formaçðes Cretácicas do Oeste Mineiro. Anais do XXXI Congresso Brasileiro de Geologia 2: 683-690, Balneário de Camboriú, SC.

COUTINHO, J.M.V. COIMBRA, A.M. -1974 - Os pesados do Barreiras na costa oriental brasileira: Estudo de áreas-fonte. Anais do XXVIII Congresso Brasileiro de Geologia 5: 27-42, Porto Alegre.

FOLK, R.L. e WARD, W.C. - 1957 - Brazos river bar. A study in the significance of grain size parameters. Journal of Sed. Petrol. 28: 3-26.

GRIM, R.E. - 1953 - Clay Mineralogy. McGraw-Hill Book Co. Inc., 342 pp.

HUBERT, J.F. - 1962 - A zircon - tourmaine - rutile maturity index and the interdependence of the composition of heavy mineral assemblages with the gross composition and texture of sandstones, Journal of Sed. Petrol., 32: 440-450.

KRUMBEIN, W.C. e GARRELS, R.M. - 1952 - Origin and classification of chemical sediments in terms of $\mathrm{pH}$ and oxidation-reduction potentials. Jour nal of Geology 60: 1-33,

KRUMBEIN, W.C. e PETTIJOHN, F.J. - 1938 - Manual of Sedimentary Petrography. Appleton Century-Crofts Inc., Nova York, $549 \mathrm{pp}$.
MILNE, I.H. E EARLEY, J.W - -1958 - Effect of source and environment on clay minerals. Bull. Amer. Assoc. Petrol. Geol. 42(2): 328-338.

MONIZ, A.C. - 1975 - Elementos de Pedologia. Editora da Universidade de São Paulo e Livros Técnicos e Cientificos, $460 \mathrm{pp}$.

PETTIJOHN, F.J. - 1975 - Sedimentary Rocks. Harper \& Row, Publishers, 3." ediça, $628 \mathrm{pp}$.

SAHU, B.K. - 1964 - Depositional mechanisms from size analysis of clastic sediments. Journal of Sed. Petrol. 34: 73-83.

SUGulo, K. - 1969 - Contribuição à geologia da Bacia do Taubaté, Vale do Paraiba, Estado de São Paulo. Bol. Especial da Fac. Fil. Ci. Letras da USP, Såo Paulo, $106 \mathrm{pp}$.

SUGUIO, K. - 1973 - Introdução a Sedimentologia. Editora Edgard Blacher Ltda. e Editora da Universidade de Sao Paulo, $317 \mathrm{pp}$.

WEAVER, C.E. - 1958 - Geologic interpretation of argillaceous sediments Part I: Origin and significance of clay minerals in sedimentary rocks. Bull. Amer. Assoc. Petrol. Geol. 42(2): 254-271.

WENTWORTH, C.K. - 1922 - A scale of grade and class terms for clastic sediments. Journal of Geology 30: 377-392. 